\title{
Chloroquine and hydroxychloroquine repositioning in times of COVID-19 pandemics, all that glitters is not gold
}

\section{Reposicionamento de cloroquina e hidroxicloroquina em tempos de pandemia de COVID-19, nem tudo que reluz é ouro}

\section{Reposicionamiento de cloroquina e hidroxicloroquina en tiempos de pandemia de COVID-19, todo lo que brilla no es oro}

Francisco José Roma Paumgartten 1 Isabella Fernandes Delgado 2 Luciana da Rocha Pitta 3 Ana Cecilia Amado Xavier de Oliveira 1

doi: 10.1590/0102-311X00088520
Drug repositioning or repurposing (DR) involves the clinical evaluation of existing medicines for new and still unapproved therapeutic indications 1,2. It has been elicited by serendipitous clinical or experimental findings, or yet by advancement of knowledge on the drug mechanism of action 1 . High throughput in silico tools involving computational techniques and artificial intelligence, however, can also predict which drugs (in use, discontinued, or shelved) are more amenable to being repurposed for medical conditions still lacking effective treatments 3,4 . Repositioning is not uncommon nor is it less profitable for pharmaceutical companies. In the United States, for instance, repurposing accounted for $25 \%$ or so drug approvals in recent years 5 .

Reduction of development timeline, costs and uncertainty are advantages of DR over de novo new molecular entity (NME) drug discovery. Since preclinical safey, manufacturing, and first-use in humans data are available, these steps of drug development are skipped. DR, however, still requires clinical trials to demonstrate that the drug, at a dose regimen, is effective and safe for a new therapeutic indication. These studies should preferably be randomized controlled trials (RCT), including a control group receiving placebo or active comparators, concealment of allocation, masking, intention-to-treat analysis, sufficiently large sample size, and assessments of reliable and valid clinical outcomes.

DR is a logical option when scientists tackle the challenge of finding effective and safe medications for emerging viral infections that spread with fast-rising death tolls. In the quest for life-saving therapies, time is certainly the most valuable asset. Investigators hear the clock ticking constantly to remind them the inexorable pace of the pandemics and its consequences. Nonetheless, although skipping steps, DR still takes time and success cannot be taken for granted.

Over 80 trials are underway to investigate whether a variety of drugs, mostly antivirals and antimalarials, could be useful to treat COVID-19 6,7. Most trials search for drugs that could alleviate the COVID-19 acute respiratory distress syndrome (ARDS) and decrease its fatality rate. A few trials were designed to find out drugs useful in proactive prophylaxis and/or to prevent COVID-19 progression from oligosymptomatic infections to severe ARDS. These goals may entail distinct modes of action and dosage regimens. Benefit-risk balance also depends on the pursued clinical goal. Drugs useful to treat ARDS are not necessarily those suitable for prophylaxis and preventive interventions.

Chloroquine (CQ), an antimalarial 4-aminoquinoline and its derivative hydroxychloroquine (HCQ), are the most notorius drugs under investigation for COVID-19.
${ }^{1}$ Escola Nacional de Saúde Pública Sergio Arouca, Fundação Oswaldo Cruz Rio de Janeiro, Brasil. 2 Vice-Presidencia de Educação Informação e Comunicação, Fundação Oswaldo Cruz, Rio de Janeiro, Brasil. 3 Instituto Nacional de Controle de Qualidade em Saúde, Fundação Oswaldo Cruz, Rio de Janeiro, Brasil.

\section{Correspondence} F. J. R. Paumgartten Laboratório de Toxicologia Ambiental, Escola Nacional de Saúde Pública Sergio Arouca, Fundação Oswaldo Cruz.

Av. Brasil 4036, Rio de Janeiro, RJ 21040-361, Brasil. paum@ensp.fiocruz.br 
The hypothesis that CQ could be useful to treat the severe acute respiratory syndrome (SARS) was advanced in 2003 , one year after an enveloped positive-stranded RNA virus (SARS-CoV) was identified as SARS's etiologic agent. This notion arises basically from in vitro data showing that CQ inhibited the replication of several enveloped RNA (and also some DNA) viruses in cell cultures 8 . Further in vitro studies demonstrated that CQ blocked cell infection by interfering with glycosylation of cellular receptors for SARS-CoV 9 and that it functioned at both entry, and at postentry stages of SARS-CoV-2 infection in Vero cells 10 . These findings were corroborated by one test in newborn mice inoculated with another human coronavirus (HCoV-OC43) that causes mild respiratory infections 11. The antiviral effects of CQ and HCQ, however, have yet to be confirmed by human trials.

Repurposing CQ-HCQ for COVID-19 poses a puzzling question that requires solving a paradox. These 4-aminoquinolines reduce T-cell and B-cell hyperactivity, and the expression of proinflammatory cytokine genes, leading to (mild) immunosuppression 12 . Owing to their immunomodulatory properties, CQ and HCQ are employed to control auto-immune disorders such as systemic lupus erythematosus, rheumatoid arthritis, and others 12 . Immunosuppression is expected to facilitate viral proliferation. Therefore, the net effect of CQ-HCQ on the viral load of COVID-19 patients shall depend on the interplay of conflicting drug actions; direct inhibition of SARS-CoV-2 replication (demonstrated in vitro) and drug-induced immunosuppression (shown in humans).

Management of hyperinflammation ("cytokines storm") in COVID-19-mediated ARDS is a challenging issue. Nothwithstanding blocking inflammatory responses, drug-induced immunodepression may facilitate viral proliferation. Some researchers believe that use of immunosuppressive drugs to treat ARDS should be better explored. Mehta et al. 13 noted that a RCT of tocilizumab (IL-6 receptor blocker) in COVID-19 and ARDS is underway. Along this line, Richardson et al. ${ }^{14}$ speculated that Janus kinase (JAK) inhibition could affect both inflammation and cellular viral entry in COVID-19. Taking the foregoing into account, it is fair to think that, if CQ (or HCQ) leads to inhibition of viral replication and also decreases cytokine massive release at the lungs, it is likely to be beneficial in the treatment of COVID-19-related ARDS. Nonetheless, immunosuppression is an undesirable side effect if CQ (or HCQ) is used for prophylaxis and/or to prevent COVID-19 progression in patients at risk for severe disease.

Furthermore, a problem for using CQ and/or HCQ for prophylaxis or prevention of ARDS in patients at risk of severe disease is their narrow margin of safety. Depending on daily doses, length of use and cumulative doses both antimalarial drugs may cause retinopathy and irreversible vision loss 15 . Overdosing and/or prolonged use of CQ/HCQ was reported to cause heart conduction disorders, low blood pressure, cardiomyopathy, cardiac arrest and death 16. CQ and HCQ also cause nausea and vomiting, loss of appetite, unpleasant metallic taste, headache, blurred vision, itching, abdominal cramps, diarrhea, tinnitus and hearing deficits, shortness of breath, weakness and mental disturbances ${ }^{15}$. This constellation of side effects discourages the use of CQ/HCQ for prophylaxis or in less severe cases of COVID-19. When prescribing CQ-HCQ for patients at elevated risk of developing ARDS, physicians should be aware that this subpopulation of patients overlaps with that at higher risk for life-threatening drug adverse events. As with any drug, risks and potential benefits of CQ-HCQ must be properly balanced. An insurmountable obstacle for weighing risks against benefits, however, is the fact that CQ-HCQ's efficacy for COVID-19 remains unproven so far.

A search (April 16, 2020) on the U.S. National Institutes of Health clinical trial registry (http:// www.ClinicalTrials.gov) identified 16 studies (recruting, active, suspended, terminated or completed) about HCQ or CQ. Eight studies were trials of CQ or HCQ for COVID-19, while the remaining ones were for other indications. Five trials of HCQ/CQ for COVID-19 were open-label studies (no masking), while one RCT is double-blinded (participant, investigator) and two RCTs are quadruple-blinded (participant, care provider, investigator, outcomes assessor) RCTs.

Open label trials entail a high risk of bias and, under the current scenario of pandemics, many investigators may have expectations about the outcome. One is a single-arm study while another open-label trial was designed to evaluate whether HCQ plus azithromycin (a drug for bacterial infections) is superior to HCQ monotherapy. Suffering from important methodological limitations, the open-label trials will not be sufficient to clarify whether CQ and HCQ are in fact useful to treat COVID-19-ARDS. The most robust evidence along this line is expected to come from three RCTs 
the design of which involves masking and concealment of allocation. These RCTs are scheduled to be completed in September 2020, April 2021 and February 2022.

Concluding, it is worth reminding those who are desperately seeking a remedy for the pandemics a powerful Shakespearean metaphor: "All that glitters is not gold - You've often heard that said. Many men have sold their souls; Just to view my shiny surface. But gilded tombs contain worms" (William Shakespeare; The Merchant of Venice, Act II, Scene VII, adapted to modern English).

\section{Contributors}

F. J. R. Paumgartten contributed to the design and writing of the first version of the manuscript. I. F. Delgado participated in the preparation and review of the manuscript. L. R. Pitta and A. C. A. X. Oliveira collaborated in the writing, bibliographic survey and revision of the manuscript.

\section{References}

1. Pushpakom S, Iorio F, Eyers PA, Escott $\mathrm{KJ}$, Hopper S, Wells A, et al. Drug repurposing: progress, challenges and recommendations. Nat Rev Drug Discov 2019; 18:41-58.

2. Talevi A, Bellera CL. Challenges and opportunities with drug repurposing: finding strategies to find alternative uses of therapeutics. Expert Opin Drug Discov 2020; 15:397-401.

3. Mak KK, Pichika MR. Artificial intelligence in drug development: present status and future prospects. Drug Discov Today 2019; 24:773-80.

4. Yella JK, Yaddanapudi S, Wang Y, Jegga AG. Changing trends in computational drug repositioning. Pharmaceuticals (Basel) 2018; 11:E57.

5. Naylor S, Kauppi DM, Schonfeld JP. Therapeutic drug repurposing, repositioning and rescue. Part II: business review. Drug Discovery World 2015; 16:57-72.

6. Rosa SGV, Santos WC. Clinical trials on drug repositioning for COVID-19 treatment. Rev Panam Salud Pública 2020; 44:e40.

7. Sanders JM, Monogue ML, Jodlowski TZ, Cutrell JB. Pharmacologic treatments for coronavirus disease 2019 (COVID-19): a review. JAMA 2020; [Epub ahead of print].

8. Savarino A, Boelaert JR, Cassone A, Majori G, Cauda R. Effects of chloroquine on viral infections: an old drug against today's diseases? Lancet Infect Dis 2003; 3:722-7.

9. Vincent MJ, Bergeron E, Benjannet S, Erickson BR, Rollin PE, Ksiazek TG, et al. Chloroquine is a potent inhibitor of SARS coronavirus infection and spread. Virol J 2005; 2:69.

\section{Additional informations}

ORCID: Francisco José Roma Paumgartten (00000002-6207-0149); Isabella Fernandes Delgado (0000-0003-0610-5324); Luciana da Rocha Pitta (0000-0002-2652-4182); Ana Cecilia Amado Xavier de Oliveira (0000-0002-5798-2258).

10. Wang M, Cao R, Zhang L, Yang X, Liu J, Xu M, et al. Remdesivir and chloroquine effectively inhibit the recently emerged novel coronavirus (2019-nCoV) in vitro. Cell Res 2020; 30:269-71.

11. Keyaerts E, Li S, Vijgen L, Rysman E, Verbeeck J, Van Ranst M, et al. Antiviral activity of chloroquine against human coronavirus OC43 infection in newborn mice. Antimicrob Agents Chemother 2009; 53:3416-21.

12. Taherian E, Rao A, Malemud CJ, Askari AD. The biological and clinical activity of antimalarial drugs in autoimmune disorders. Curr Rheumatol Rev 2013; 9:45-62.

13. Mehta P, McAuley DF, Brown M, Sanchez E, Tattersall RS, Manson JJ, et al. COVID-19: consider cytokine storm syndromes and immunosuppression. Lancet 2020; 395:1033-4.

14. Richardson P, Griffin I, Tucker C, Smith D, Oechsle O, Phelan A, et al. Baricitinib as potential treatment for 2019-nCoV acute respiratory disease. Lancet 2020; 395:E30-1.

15. Haładyj E, Sikora M, Felis-Giemza A, Olesińska M. Antimalarials - are they effective and safe in rheumatic diseases? Reumatologia 2018; 56:164-73.

16. Roos JM, Aubry MC, Edwards WD. Chloroquine cardiotoxicity: clinicopathologic features in three patients and comparison with three patients with Fabry disease. Cardiovasc Pathol 2002; 11:277-83.

Submitted on 18/Apr/2020

Approved on 27/Apr/2020 